\title{
Geoscience Laser Altimetry System (GLAS) Loop Heat Pipe Anomaly and On Orbit Testing
}

\author{
Charles Baker ${ }^{1}$, Dan Butler ${ }^{2}$, Eric Grob ${ }^{3}$ \\ NASA/Goddard Spaceflight Center, Greenbelt, MD 20771 \\ and \\ Peggy Jester ${ }^{4}$ \\ SGT, Wallops Island, VA 23337, USA
}

\begin{abstract}
The Geoscience Laser Altimetry System (GLAS) is the sole instrument on the ICESat Satellite. On day 230 of 2003, the GLAS Component Loop Heat Pipe (CLHP) entered a slow circulation mode that resulted in the main electronics box reaching its hot safing temperature, after which the entire instrument was turned off. The CLHP had a propylene working fluid and was actively temperature controlled via a heater on the compensation chamber. The slow circulation mode happened right after a planned propulsive yaw maneuver with the spacecraft. It took several days to recover the CLHP and ensure that it was still operational. The recovery occurred after the entire instrument was cooled to survival temperatures and the CLHP compensation chamber cycled on a survival heater. There are several theories as to why this slow circulation mode exhibited itself, including: accumulation of Non-Condensible Gas (NCG), the secondary wick being under designed or improperly implemented, or an expanded (post-launch) leak across the primary wick. Each of these is discussed in turn, and the secondary wick performance is identified as the most likely source of the anomalous behavior. After the anomaly, the CLHP was controlled to colder temperatures to improve its performance (as the surface tension increases with lower temperature, as does the volume of liquid in the compensation chamber) and only precursor pulses occurred later in the mission. After GLAS's last laser failed, in late 2009, a decision was made to conduct engineering tests of both LHPs to try and duplicate this flight anomaly. The engineering tests consisted of control setpoint changes, sink changes, and one similar propulsive Yaw maneuver. The only test that showed any similar anomaly precursors on the CLHP was the propulsive maneuver followed by a setpoint increase. The ICESat Satellite was placed in a decaying orbit and ended its mission on August 30, 2010 in Barents Sea.
\end{abstract}

\section{Introduction}

ICESat (Ice, Cloud, and land Elevation Satellite) was the benchmark Earth Observing System mission for measuring ice sheet mass balance, cloud and aerosol heights, as well as land topography and vegetation characteristics. From 2003 to 2009, the ICESat mission provided multi-year elevation data needed to determine ice sheet mass balance as well as cloud property information, especially for stratospheric clouds common over polar areas. It also provided topography and vegetation data around the globe, in addition to the polar-specific coverage over the Greenland and Antarctic ice sheets. ICESat was baselined as a three year mission with a five year goal.

GLAS (the Geoscience Laser Altimeter System) was the first laser-ranging instrument for continuous global observations of Earth from a $600 \mathrm{~km}$ polar non-synchronous (all Beta angle) orbit. At 40 arcsec FOV and $104 \mathrm{~mJ} / 40$

\footnotetext{
${ }^{1}$ Senior Systems Engineer, Systems Engineering Services and Advanced Concepts Branch, Code 592.

${ }^{2}$ Associate Branch Head, Thermal Engineering Branch, 545.

${ }^{3}$ Thermal Chief Engineer, Thermal Engineering Branch, 545.

${ }^{4}$ Department Head, Cryospheric Sciences Lab 614.1.
} 
$\mathrm{Hz}$ Laser system, the Laser system and precision Stellar Reference System (SRS) required a capable and stable Optical Bench. GLAS was built at the NASA Goddard Space Flight Center (GSFC) and it was designed to measure ice-sheet topography and associated temporal changes. This was to be the first global baseline of the polar icecaps to a $10 \mathrm{~cm}$ absolute precision. GLAS operated over land and water and provided along-track topography.

The thermal control system of GLAS required tight, stable temperature control under significantly varying sink temperatures, low heater power, and significant capacity to handle the instrument power of $110 \mathrm{~W}$ on the Laser side (with $45 \mathrm{~kg}$ of thermal mass) and $143 \mathrm{~W}$ on the component side (60 kg of thermal mass). To accomplish this, the thermal system had two independently controlled propylene Loop Heat Pipe (LHP) systems both fed by a network of ammonia Constant Conductance Heat Pipes (CCHPs). The Laser side had a Loop Heat Pipe (LHP) hereafter referred to as a Laser LHP or LLHP. The electronics side LHP was called the Component Loop Heat Pipe (CLHP) of which most of this paper refers. The electronics and Lasers were thermally isolated from the deck via titanium flexures to minimize gradients on the optical bench. The actively controlled LHP systems had heaters on their compensation chambers that were electronically controlled to maintain the temperature of GLAS's Laser and Electronics systems (also effectively controlling the bench temperature). By mechanically connecting the liquid return line to the vapor line near the evaporator body, the required heater power was very low for the precise thermal control (about 4-5 W per LHP). Fig 1 shows a simple schematic of the system.
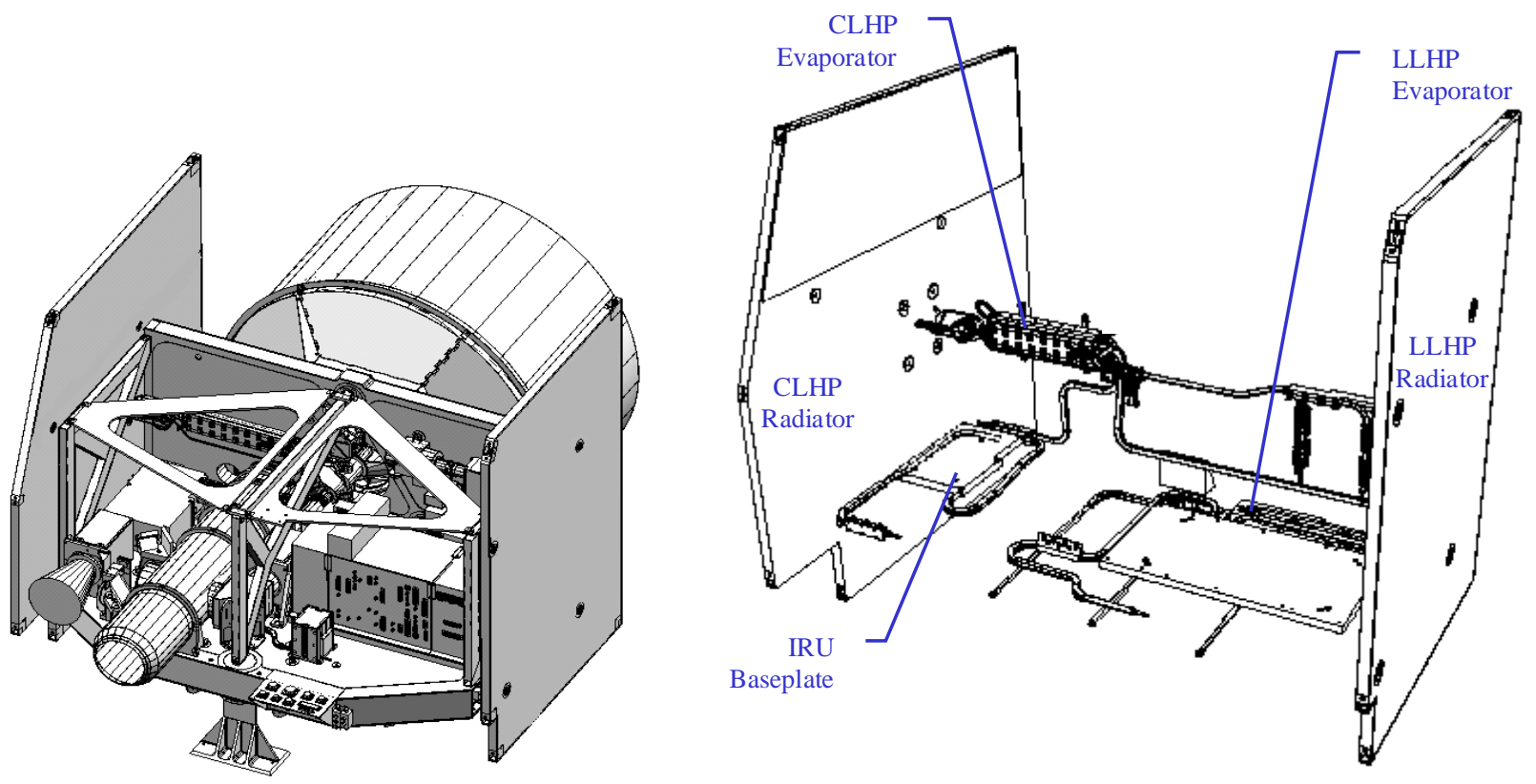

Figure 1. GLAS Instrument Mechanical Model (Left), Heat Pipe Network and LHPs (Right)

During the 6 year mission, only one significant thermal performance issue occurred. This happened in the fall of 2003 (the year ICESAT launched) when the GLAS Component Loop Heat Pipe (CLHP) did not provide adequate cooling to the Component thermal system (and therefore the GLAS electronics) following the Yaw maneuver at Beta $32^{\circ}$ (which has the hottest and most transient sink.) The yaw maneuver produced around $5 \times 10^{-5} \mathrm{~m} / \mathrm{s}^{2}$ of acceleration. Though the CLHP appeared to continue to circulate fluid, the active control of the setpoint was lost. The week before the yaw maneuver, similar temperature excursions were observed, after which the CLHP recovered (or appeared to). Fig 2 shows the overall rise of the temperature, due to the slow circulation mode directly after an orbit maneuver of the ICESat Spacecraft. The increase continued until the instrument safed itself when the temperature limit on the MEB was reached. In the last several months before GLAS was decommissioned, tests were conducted with the instrument to try to reproduce the observed CLHP slow circulation from 2003. The test were unsuccessful with the exception of the last test, which included the yaw maneuver that was similar to the one linked to the original anomaly and followed by a setpoint increase which resulted in some precursor blips that will 
be discussed in Section III. This paper discusses what was observed on the day of the anomaly in 2003 and what tests were conducted in an attempt to reproduce the thermal anomaly in 2010.

\section{Flight Anomaly}

GLAS CLHP On-Orbit Day 229+24 hours CLHP De-Prime right after Yaw

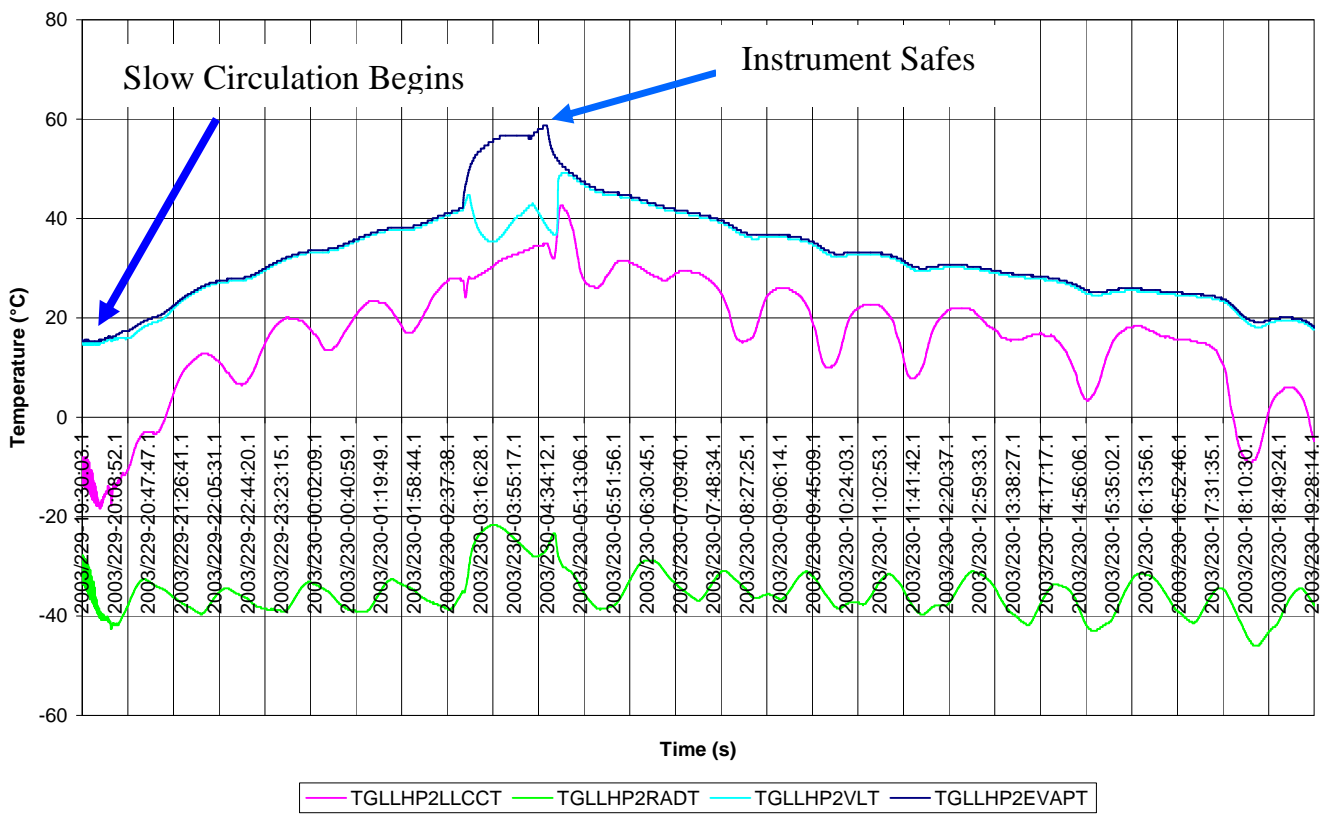

Figure 2. Temperature rise due to slow circulation mode following Yaw Maneuver

The available flight telemetry on the CLHP consists of 4 telemetry points: TGLLHP2EVAPT (Evaporator), TGLLHP2VLT (Vapor Line), TGLLHP2LLCCT (Liquid Line at CC entrance), TGLLHP2RADT (liquid line exit from condenser); respectively located on the LHP Evaporator near the starter heater, the vapor line after exiting the coupling blocks (which is the saturation vapor), the liquid line after the coupling blocks but before the compensation chamber, and the liquid line exit directly from the radiator (see Fig 3). The TGLLHP2EVAPT is used to measure the relative temperature of the component system (as the electronic components are coupled to the evaporator via constant conductance heat pipes (see Fig 1). 


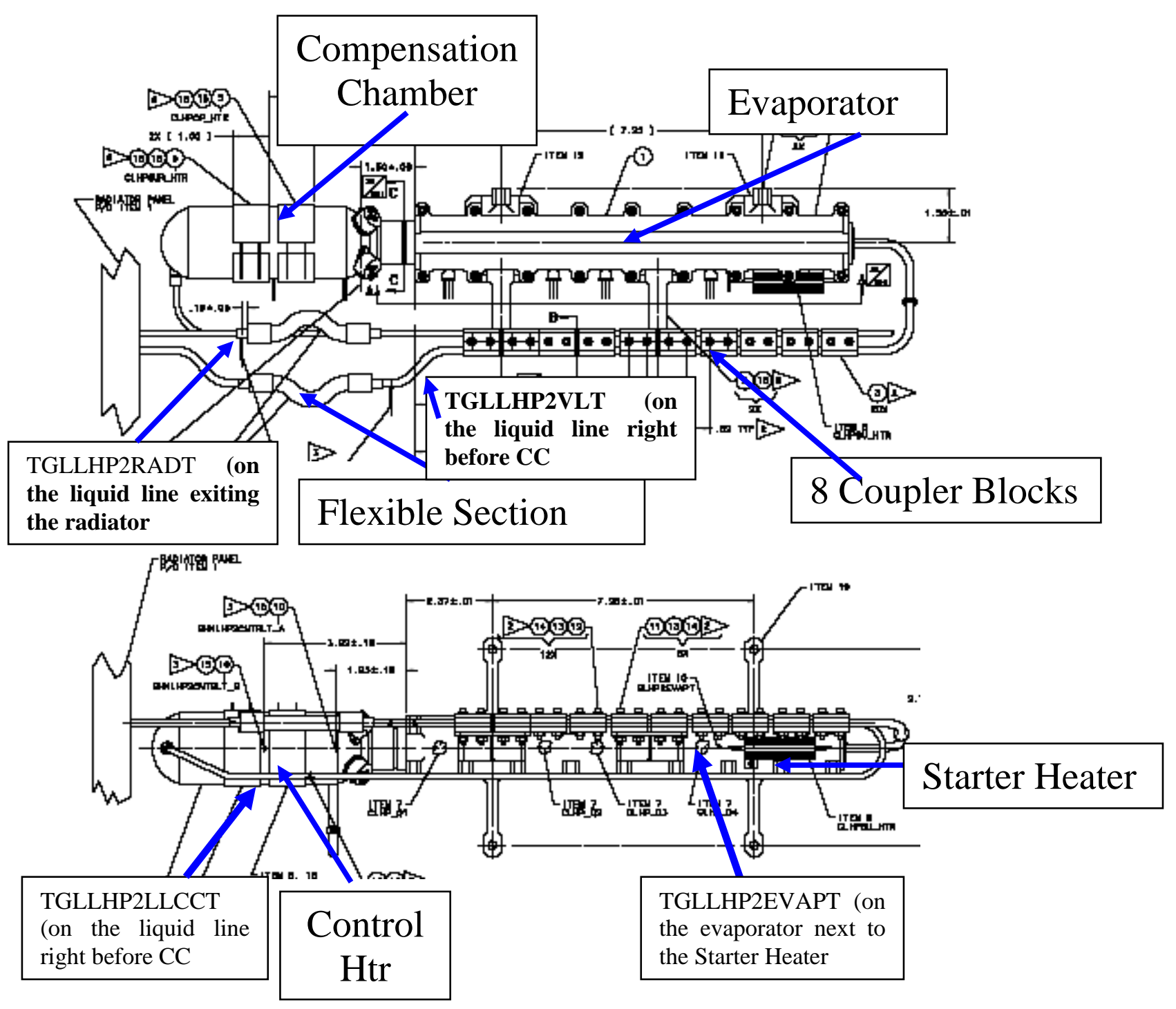

Figure 3. Component LHP Telemetry, Starter Heater and Operational Heater.

\section{Flight Recovery}

An attempt to quickly re-prime and pre-condition the LHP two days later resulted in the LHP starting quickly but failing soon after, as shown in Fig 4. After the LHP was operated cold on the survival heater for many hours, the LHP was slowly (decreasing the setpoint increase rate to $1 / 36$ of the previous rate) raised back to operating range and operated with a full load plus a $60 \mathrm{~W}$ starter heater without entering the slow circulation mode for the remainder of the mission. 
GLAS CLHP On-Orbit Day 232+30 hours 2nd attempt to reprime and restart (not successful)

Note: $\mathrm{CC}$ was raised $2^{\circ} \mathrm{C}$ above Evap for 15 minutes before restart)

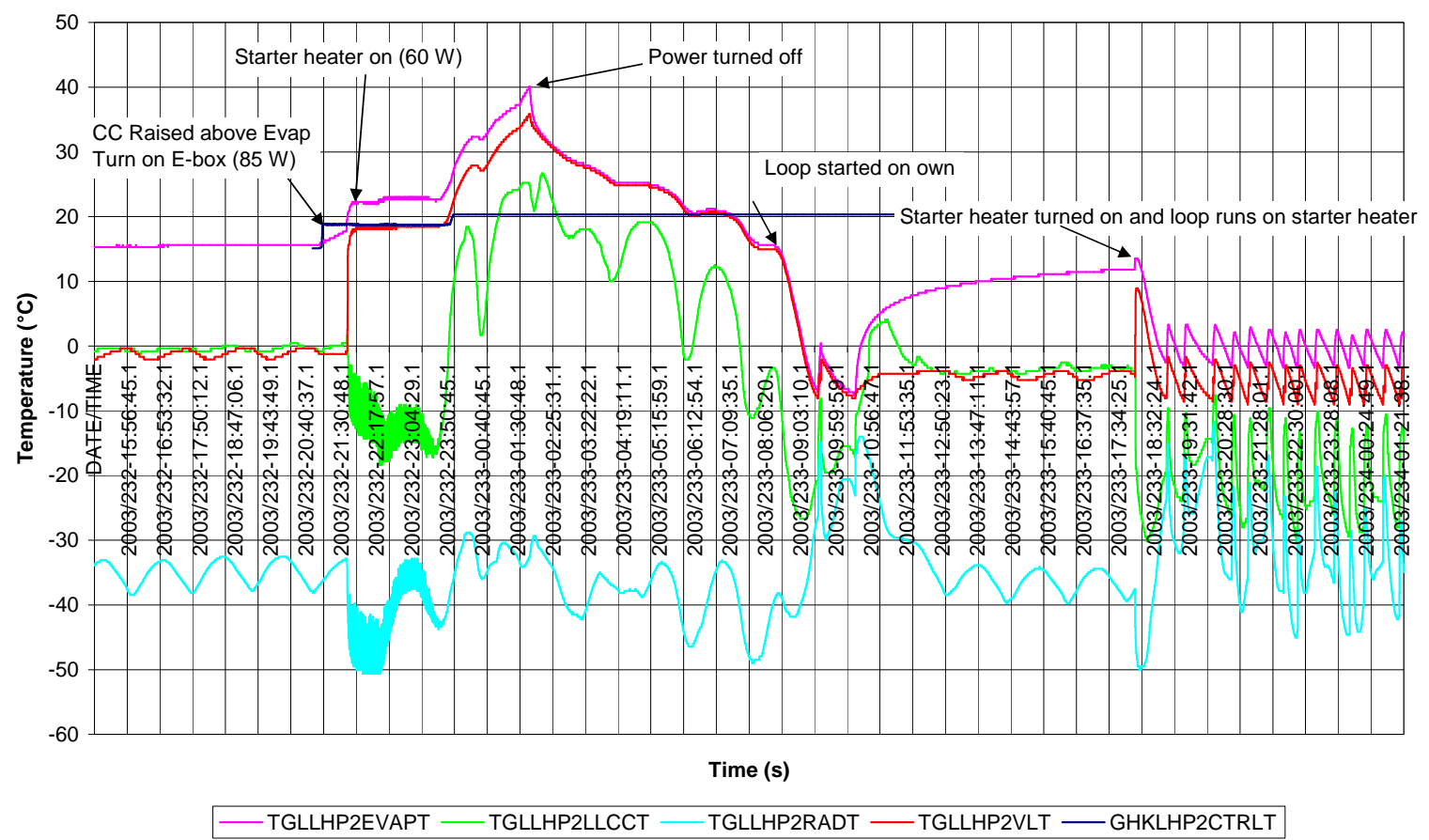

Figure 4. CLHP Second Start-up attempt pre-conditioning, failure, and recovery

In order for LHPs to circulate the working fluid and maintain low conductance, two things have to be true: the primary wick heat leak from the vapor side to the liquid side (or CC side) has to be less than sensible heat returning from the liquid line and the primary wick needs to be fully primed to enable a pressure difference from the vapor side to the liquid side. The pressure difference initiates the flow of the working fluid through the radiator returning it into the CC where it is fed back into the wick through surface tension. Slow circulation represents a case where either vapor is penetrating through the wick (due to a partial dryout) or excessive heat is conducted across the wick which lowers the pressure difference across the wick effectively diminishing the vapor flow and therefore the electronics have insufficient heat conducted to the sink. The electrical dissipation in the electronics is then not conducted away by the LHP and the electronics increase in temperature.

Once the LHP enters slow circulation, the condition that caused it to enter slow circulation (localized wick dryout and vapor penetration) is worsened as the heat load on the LHP evaporator decreases as more of the dissipated electrical energy goes into sensible heating of the electronic components. What was unique about the spacecraft maneuver was that there was a relatively minor g load pulling liquid out of the evaporator core at the same time as the sink condition was cooling, which also tends to draw liquid from the evaporator core and CC. The interesting part about the anomaly's transition to slow cirulation is that it did not recover to normal circulation, where throughout the mission pre-cursor blips (similar to those seen in Fig 5) were indicative of a susceptibility of sustained slow circulation, but the slow circulation was recovered from and never resulted in an subsequent sustained slow circulation. The proximity of the original pre-cursor blips (as a result only of sink transience) and then the sustained slow circulation after the extra kick from the yaw manuever is that it might be possible to anticipate subsequent slow circulation modes by watching for pre-cursor blips. Then by flushing the LHP through a temperature setpoint drop, the condition improved and the blips disappear, indicating the vapor penetration condition was alleviated.

Nominal operations of the LHP resumed after flushing of the CLHP with the survival heater. After this slow circulation mode was experienced, there were observations of the slow circulation precursors during later flight operations, as shown below in Fig 5, however the slow circulation mode was averted by lowering the CLHP 
operating temperature by a few degrees, which flushed the evaporatore core with liquid. It was important to flush the evaporator after observing the blips on subsequent blip precursors. There had been blip precursors before the Fig 2 slow circulation run away 3 days prior to the Yaw maneuver. Whatever was affecting the LHP at that time must have remained and the peturbation of the Yaw maneuver must have exacerbated the problem to cause the slow circulation. In Fig 5, the temperature setpoint decrease is observable and then the precursor blips ceased.
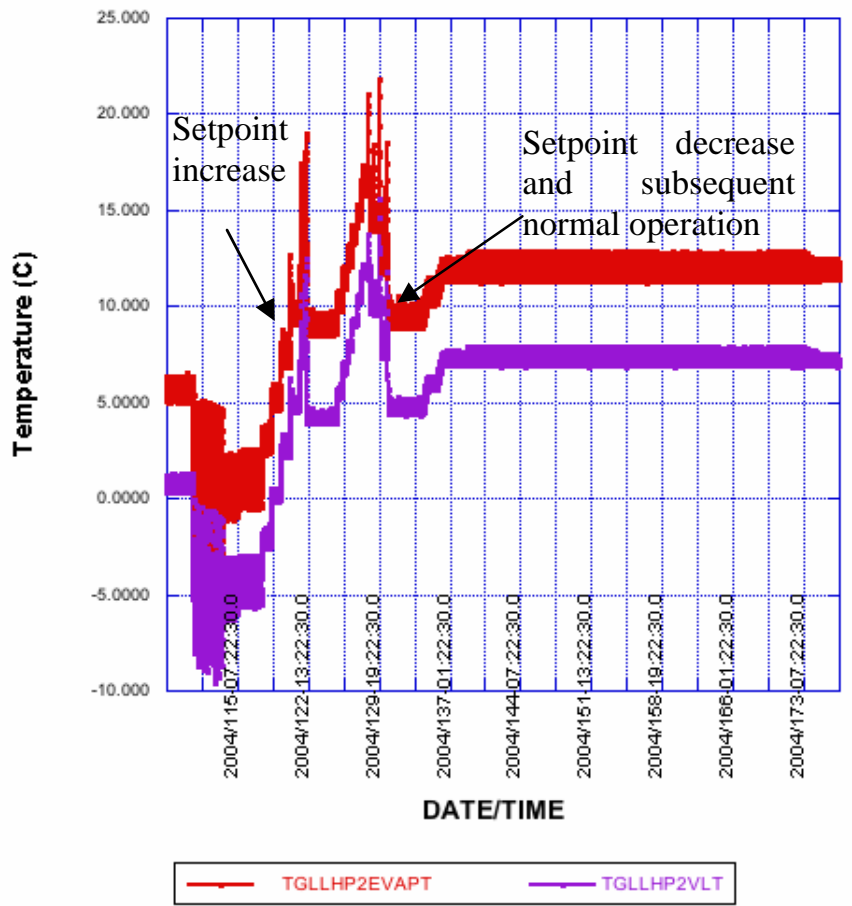

Figure 5. Further observations of slow circulation precursors on-orbit

Based on the original anomaly and observations of slow circulation precursors, several theories as to the cause of the slow circulation mode were developed.

\section{Possible Causes for the Temperature Anomalies}

Potential causes for the slow circulation mode were categorized according to likelihood, and investigated accordingly.

Remote likelihood causes for the slow circulation included:

- Primary wick or seals damaged allowing vapor pentration from the vapor side into the evaporator core (ruled out since the LHP recovered)

- Particulates block primary or secondary wick or transport lines (not explained by sensitivity to sink dropping and sensitivity to $\mathrm{g}$ forces)

- Loss of liquid charge due to a slow leak in the system - ruled out due to continued operation of the loop over the life of the mission.

The most likely source of the slow circulation mode was:

- A bubble (likely vapor) resulting in a partial dryout of the primary wick. The secondary wick is inadequate to pump around the bubble, resulting in a vapor penetration of the primary wick. The LHP utilizes propylene working fluid, and would be more sensitive to inadequate workmanship of the secondary wick due to its lower pumping capability as compared to an ammonia charged LHP. As this issue was never seen on the LLHP, it was perceived as a one of a kind workmanship issue of the CLHP. The g load of the manuever stacked on a rapidly cooling condenser would have allowed this bubble to grow. 
General Observations

- $\quad$ Temperature excursions were seen on cold portion of orbit when the condenser cooling (due to a colder sink) results in a liquid transfer from the Compensation Chamber and Evaporator Core to the Condenser see Fig 6

- $\quad$ LHP Runs better at colder temperatures - more liquid fill in the compensation chamber due to density changes

GLAS CLHP On-Orbit Day 229+24 hours CLHP De-Prime right after Yaw

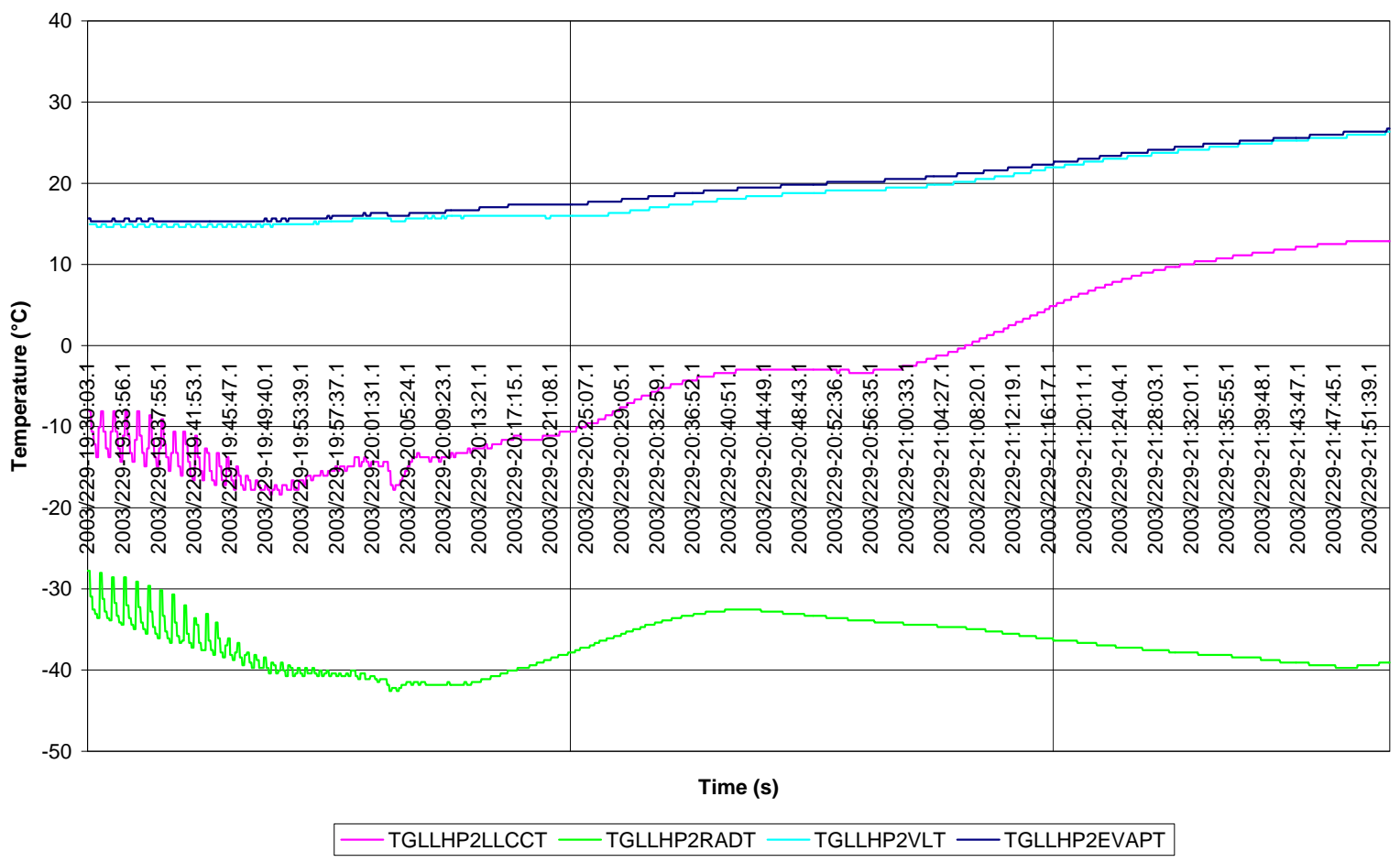

Figure 6. Blow up of the original CLHP De-Prime showing the Liquid Line temperature drop and then slow circulation mode commence

\section{GLAS Testing in $\mathbf{2 0 1 0}$}


Table 1. GLAS Post Science Mission Slow Circulation Mode Test Program

\begin{tabular}{|c|c|c|}
\hline Activity & YYYY/DDD-hh:mm:ss.sss & Comment \\
\hline Laser LHP Setup & 2010/096-17:10:08 & $\begin{array}{l}\text { Laser warmup heaters on; laser } 1 \text { power on; llhp starter heater } \\
\text { on }\end{array}$ \\
\hline Warm the LLHP Radiator & $\begin{array}{l}\text { 2010/096-18:00:00.00 - } \\
\text { 2010/096-18:30:00.00 }\end{array}$ & $\begin{array}{l}\text { Spacecraft Maneuver to point LLHP radiator to nadir for } 30 \\
\text { minutes }\end{array}$ \\
\hline $\begin{array}{l}\text { Rapidly raise the LLHP setpoint to } \\
14 C\end{array}$ & $\begin{array}{l}\text { 2010/097-09:58:30 } \\
\text { 2010/097-14:03:30 }\end{array}$ & At the rate of 1 count per 3.5 minutes \\
\hline $\begin{array}{l}\text { Rapidly raise the LLHP setpoint to } \\
21.5 \mathrm{C}\end{array}$ & $\begin{array}{l}2010 / 098-13: 12: 30 \\
2010 / 098-16: 56: 30\end{array}$ & At the rate of 1 count per 3.5 minutes \\
\hline $\begin{array}{l}\text { Rapidly raise the LLHP setpoint to } \\
29 \mathrm{C}\end{array}$ & $\begin{array}{l}2010 / 099-13: 47: 00 \\
2010 / 099-17: 17: 00\end{array}$ & At the rate of 1 count per 3.5 minutes \\
\hline LLHP setpoint set to $22.5 \mathrm{C}$ & 2010/099-22:32:44 & $\begin{array}{l}\text { To prepare for raising the setpoint in one large step; set to } 22.5 \\
\text { by mistake should have been set to } 20 \mathrm{C}\end{array}$ \\
\hline LLHP setpoint set to $25 \mathrm{C}$ & 2010/102-14:58:13 & Raise in one large step \\
\hline Repeat LLHP setpoint set to $20 \mathrm{C}$ & $2010 / 102-22: 37: 32$ & $\begin{array}{l}\text { To prepare for raising the setpoint in one large step (first time } \\
\text { test was done the setpoint was incorrect) }\end{array}$ \\
\hline Repeat LLHP setpoint set to $25 \mathrm{C}$ & 2010/103-17:55:31 & Raise in one large step \\
\hline Component LHP Setup & 2010/103-00:00:00 & $\begin{array}{l}\text { CLHP starter heater on; raise CLHP setpoint to } 15 \mathrm{C} \text { (for clarity } \\
\text { out of sequence) }\end{array}$ \\
\hline Warm the CLHP Radiator & $\begin{array}{l}2010 / 103-19: 15: 00 \\
2010 / 103-19: 45: 00\end{array}$ & $\begin{array}{l}\text { CLHP setpoint }=15 \mathrm{C} \text {; Spacecraft Maneuver to point CLHP } \\
\text { radiator to nadir for } 30 \text { minutes }\end{array}$ \\
\hline CLHP setpoint set to $0 \mathrm{C}$ & 2010/104-16:46:05 & To prepare for next activity \\
\hline Warm the CLHP Radiator & $\begin{array}{l}2010 / 105-16: 20: 00 \\
2010 / 105-16: 50: 00\end{array}$ & $\begin{array}{l}\text { CLHP setpoint }=0 C \text {; Spacecraft Maneuver to point CLHP radiator } \\
\text { to nadir for } 30 \text { minutes }\end{array}$ \\
\hline Rapidly raise CLHP setpoint to $10 \mathrm{C}$ & $\begin{array}{l}2010 / 106-09: 22: 00 \\
2010 / 106-17: 02: 00\end{array}$ & At the rate of 1 count per 5 minutes \\
\hline Rapidly raise CLHP setpoint to $15 \mathrm{C}$ & $\begin{array}{l}2010 / 109-10: 46: 00 \\
2010 / 109-14: 26: 00\end{array}$ & At the rate of 1 count per 5 minutes \\
\hline Rapidly raise CLHP setpoint to $20 \mathrm{C}$ & $\begin{array}{l}2010 / 110-11: 11: 00 \\
2010 / 110-14: 36: 00\end{array}$ & At the rate of 1 count per 5 minutes \\
\hline CLHP setpoint set to $0 \mathrm{C}$ & 2010/113-16:46:01 & To prepare for next activity \\
\hline Rapidly raise CLHP setpoint to $10 \mathrm{C}$ & $\begin{array}{l}2010 / 116-13: 00: 02 \\
2010 / 116-17: 50: 02\end{array}$ & $\begin{array}{l}\text { Repeat at a faster rate since no blips were observed: At the rate } \\
\text { of } 2 \text { counts per } 5 \text { minutes }\end{array}$ \\
\hline Rapidly raise CLHP setpoint to $15 \mathrm{C}$ & $\begin{array}{l}2010 / 117-13: 00: 02 \\
2010 / 117-14: 55: 02\end{array}$ & $\begin{array}{l}\text { Repeat at a faster rate since no blips were observed: At the rate } \\
\text { of } 2 \text { counts per } 5 \text { minutes }\end{array}$ \\
\hline Rapidly raise CLHP setpoint to $20 \mathrm{C}$ & $\begin{array}{l}2010 / 117-13: 00: 02 \\
2010 / 117-14: 45: 02\end{array}$ & $\begin{array}{l}\text { Repeat at a faster rate since no blips were observed: At the rate } \\
\text { of } 2 \text { counts per } 5 \text { minutes }\end{array}$ \\
\hline LLHP setpoint set to $20 \mathrm{C}$ & 2010/137-17:23:06 & Laser temperatures breaking red limits \\
\hline CLHP Setpoint set to $14.5 \mathrm{C}$ & 2010/158-17:33:01 & Prior to Yaw maneuver to airplane mode \\
\hline Yaw to airplane mode & 2010/160-14:15:00 & \\
\hline CLHP EVAPT blip & 2010/161-22:30 & \\
\hline CLHP Setpoint set to OC & 2010/163-01:09:50 & After Yaw maneuver \\
\hline Rapidly raise CLHP setpoint to $10 \mathrm{C}$ & $\begin{array}{l}2010 / 165-09: 15: 00 \\
2010 / 165-16: 55: 00\end{array}$ & At the rate of 1 count per 5 minutes \\
\hline Rapidly raise CLHP setpoint to $15 \mathrm{C}$ & $\begin{array}{l}2010 / 166-11: 50: 00 \\
2010 / 166-15: 30: 00\end{array}$ & At the rate of 1 count per 5 minutes \\
\hline Rapidly raise CLHP setpoint to $20 \mathrm{C}$ & $\begin{array}{l}2010 / 167-12: 15: 00 \\
2010 / 167-15: 40: 00\end{array}$ & At the rate of 1 count per 5 minutes \\
\hline
\end{tabular}

Following the end of the GLAS science campaign, a series of instrument tests were initiated to explore the causes of the slow circulation mode. The intention of the test was to reproduce the flight failure. The Test program is shown in Table 1. A sink change test is shown in Fig 7 and a setpoint change test. This test did not result in any precursor blips. 


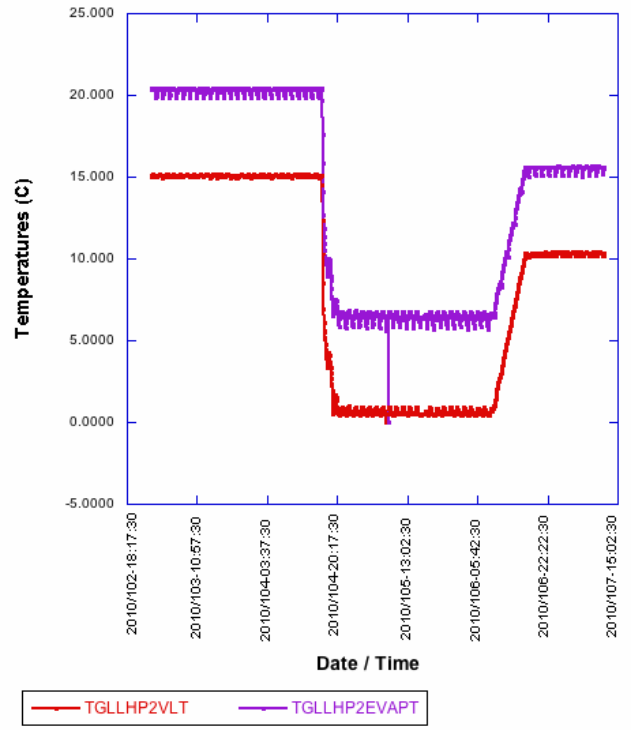

Figure 7. Sink Change Test $\left(\right.$ at $\left.0^{\circ} \mathrm{C}\right)$ and Setpoint Change Test.

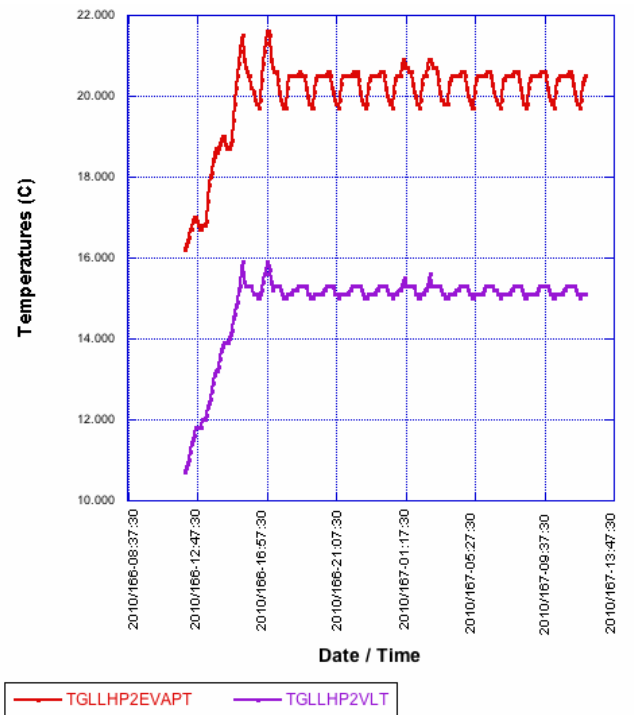

Figure 8. EVAPT Blips (slow circulation precursors) resulting from combination of setpoint changes and high control points

As is seen, neither sink transients (rotating the CLHP radiator to face the Earth versus deep space), nor setpoint changes were successful in forcing the CLHP to start to show precursors for slow circulation mode. Only by combining setpoint changes and high control points after the yaw maneuver, were the precursor blips observed (Fig 8). As was noted earlier, these pre-cursor blips may be indications of a susceptibility to future sustained slow circulation mode. Fig 8 shows the only precursors for slow circulation that occurred during the testing a few days after the Yaw maneuver and when the LHP setpoint was well above its nominal setting (this graph has a setpoint of 20 C.) The previous precursor blips during the baseline mission occurred when the CLHP was set at 15 C in the original slow circulation runaway and at $7.5 \mathrm{C}$ during the Fig 5 blips. Note also that after the setpoint was dropped $5^{\circ} \mathrm{C}$ that the precursor blips stopped (which Fig 5 shows.) The effect of dropping the setpoint transfers fluid from the condenser into the evaporator core rapidly potentially re-wetting the dried out wick section.

\section{Conclusions}

The loss of temperature control that occurred in 2003 with the CLHP was very unique. The rigorous testing in 2010 was not able to replicate the source of the slow circulation, but was only able to replicate the precursors by combining setpoint settings well above normal GLAS operating conditions with a yaw maneuver several days earlier, which was similar to the conditions present during the on-orbit anomaly. The LLHP was also tested with the same rigor and did not show the precursors nor did it suffer a loss of temperature control during the mission. The superior performance of the LLHP must mean the secondary wick (whose function is to keep the primary wick wetted) must have been more successfully implemented in the LLHP than the CLHP. It should be pointed out that there were some last minute design changes and rework to the LLHP and CLHP loops, which could have increased the chance that there were was a workmanship issue with the CLHP.

During CLHP testing, only the combination of setpoint transients and the yaw maneuver (small g's) were sufficient to cause precursor blips on the GLAS CLHP. This can have two implications: 1) the slow circulation modes observed by GLAS in 2004 were much more a collusion of unlikely events than previous thought; 2) reproducing the conditions where blips occur or slow circulation mode itself occurs are more difficult than can easily be replicated during in-flight testing. The workmanship differences between the CLHP and LLHP secondary wicks (as measured by the more reliable LLHP performance) could have been discovered on the ground if GSFC had conducted secondary wick tests like the Naval Research Lab has been advocating. It is recommended that similar testing be conducted on all propylene LHPs in the future due to the lower pumping capability of propylene and therefore the greater sensitivity to workmanship differences in secondary wicks. This is done by elevating the 
portion of the LHP without a reservoir attached and verifying continued performance with a fluid inventory resulting in a vapor space at the wick dead end.

Operationally, for the rest of the mission following the sustained slow circulation, the CLHP setpoint was kept lower than was desired by the science team out of concern for a re-occurence of slow circulation. This proved to a be a good operational workaround thermally as the slow circulation mode never returned (though we saw precursor blips). But this resulted in pointing issues (due to CTE effects seen first in Instrument Thermal Vacuum as the instrument cooled from its perfect alignment at ambient) between the Laser and the receiver which caused the return

pulses to be focused at the edge of the field of view of the receiver. This approach balanced the impact of further slow circulation risk while maintaining most of the instrument performance. No sustained slow circulation modes occurred after the first one.

\section{REFERENCES}

"Geoscience Laser Altimeter System (Glas) Loop Heat Pipes -An Eventful First Year On-Orbit”, 2004-01-2558, ICES 2004, E. Grob, C. Baker and T. McCarthy, NASA Goddard Space Flight Center

"In-Flight Thermal Performance of the Geoscience Laser Altimeter System (GLAS) Instrument”, ICES 2003, 03ICES-274, E. Grob, C. Baker , and T. McCarthy, NASA Goddard Space Flight Center

“Basics of Loop Heat Pipe Temperature Control”, 1999-01-2012 ICES 1999, Nikitkin, M. M.

"The Loop Heat Pipe Experimental Onboard the Granat Spacecraft," 6th European Symposium on Space Environmental Control Systems 1997, Orlov, A., Gocharov, K, Kotlyarov, E., Tyklina, T., Ustinov, S., and Y. Maidanik,

“Loop Heat Pipe Flight Experiment”, 98ES-80 ICES Conference Proceedings 1998, Baker, C. L., Bienert, W. B, Ducao, A. S.

“Geoscience Laser Altimeter System (GLAS) Final Test Report of DM LHP TV Testing”, NASA Technical Publication (NASA/TP-2000-209898,) National Aeronautics and Space Administration, Baker, C. L., Goddard Space Flight Center, 2000. 